\title{
Bloqueo femoral continuo: Opción para control de dolor en reemplazo total de rodilla con movilización inmediata
}

\author{
Acosta Larrosa M. ${ }^{1,2}$, Díaz, N. ${ }^{1}$, Carabajal JM. ${ }^{1}$, Rojas S. ${ }^{1}$ \\ 1 Hospital Regional Ramón Carrillo, Santiago del Estero, Argentina. \\ 2 Santiago del Estero.
}

Introducción: La cirugía de reemplazo total de rodilla está asociada a dolor posoperatorio que se cataloga como intenso por lo que cual es necesario un adecuado manejo del dolor para una rehabilitación temprana. Esto genera un desafío para los anestesiólogos ya que no hay un acuerdo sobre que esquema analgésico es mejor. El bloqueo femoral continuo es una opción válida para su control.

Descripción del caso: Paciente masculino de 55 años, 90 kilos, BMI 30. Antecedentes patológicos hipertensión. Antecedentes quirúrgicos: artroplastia total de rodilla, extracción de prótesis con colocación de espaciador con pésimo manejo del dolor posoperatorio en ambos procedimientos. Cirugía: artroplastia total de rodilla. Intraoperatorio: monitoreo de signos vitales con oximetro de pulso, presión arterial no invasiva y cardioscopio. Sedación con Midazolam $3 \mathrm{mg}$ cada $45 \mathrm{~min}$. Se realiza bloqueo neuroaxial subaracnoideo con bupivacaina hiperbárica $0,5 \% 15 \mathrm{mg}$ + clonidina $80 \mathrm{mcg}$, seguido de bloqueo femoral izquierdo con bupivacaina isobárica $0,125 \%$ sin epinefrina y colocación de catéter bajo guía ecográfica y neuroestimulación. Duración de cirugía 130 minutos, sin complicaciones. Pasa a sala común. Posoperatorio: se indica analgesia con infusión continua de bupivacaina $0,125 \%$ sin epinefrina a $10 \mathrm{ml} / \mathrm{h}$, diclofenac $75 \mathrm{mg}$ cada $12 \mathrm{~h}$ y dipirona 2 gramos cada $8 \mathrm{~h}$ endovenoso. Comienza con rehabilitación a las 2 h. Control exitoso del dolor con EVA 2/10 en la hora 1, 6, 12, 18, 24, 36 y 48 h luego de la cual se retira el catéter femoral manteniendo la indicación de diclofenac $75 \mathrm{mg}$ cada $12 \mathrm{~h}$ endovenoso y rescate con tramadol 37,5 mg más paracetamol $325 \mathrm{mg}$ vía oral y logrando un adecuado control del dolor sin necesidad de rescate. Alta hospitalaria al $4^{\circ}$ día.

Discusión: Existen múltiples opciones analgésicas y cada una con ventajas y contras por lo que no hay acuerdo sobre un esquema único y superador. El bloqueo femoral continuo presenta ciertas ventajas frente a analgesia endovenosa en relación al uso de opioides y sus efectos adversos. En nuestro caso el manejo del dolor fue óptimo, generando mayor confort y satisfacción en el paciente en comparación con cirugías previas. Esta técnica es una de las mejores opciones en nuestro ámbito ya que no contamos con personal idóneo en sala de internación para manejar otro tipo de analgésicos como son los opioides.

https://doi.org/10.25237/congresoclasa2019.92 